\title{
THE EFFECT OF TWO PROTECTIVE OCCLUSAL SCHEMES OF IMMEDIATELY LOADED MINI-IMPLANT SUPPORTED MANDIBULAR OVERDENTURE ON MASSETER MUSCLE ACTIVITY AND RIDGE KERATINIZATION
}

\author{
Essam A. Aziz* and Nermine R. Amin**
}

\begin{abstract}
Background: Lingualized and monoplane occlusal (LO and $\mathrm{MO}$ ) schemes are the most protective schemes regarding the prognosis of the immediately loaded mini-implants. The occlusal scheme in complete overdentures is a prime factor that affects masticatory efficiency that will subsequently determine the forces transmitted through the denture base to the denture foundation thus affecting ridge keratinization reaction as well as the degree of mini-implant osseo-integration .
\end{abstract}

Material and Methods: Twenty completely edentulous male patients were divided into two equal groups. Complete upper and lower dentures were constructed for all patients with their artificial teeth set following the LO scheme for group I patients and the MO scheme for group II patients. Four mini-implants were installed interforaminally and immediately loaded in each patient. Electromyographic (EMG) records, keratinization index (KI) values and periotest values (PTVs) were collected at the time of denture delivery, one month and four months after denture delivery.

Results: Median EMG and KI values for LO and MO groups showed a significant increase after 1 and 4 months. Similarly, the median PTVs for LO group increased along the follow up periods showing a significant increase after 1 and 4 months. However, the median PTVs for MO group showed a perculating pattern showing a significant increase after 1 month followed by a significant decrease after 4 months of denture delivery. Changes in median KI values for MO group showed a significant difference than that for LO group after 1 and 4 months. Changes in median PTVs for LO group showed a significant difference than that for MO group after 4 months only. A significant inverse correlation was noticed between changes in EMG records and PTVs as well as between PTVs and KI values after 4 months of denture delivery.

* Assistant Professor, Removable Prosthodontics Department, Faculty of Oral and Dental Medicine, Cairo University.

** Lecturer, Oral Pathology Department, Faculty of Oral and Dental Medicine, Cairo University. 
Conclusions and Recommendation: From the results of this study it can be concluded that:

1- Both occlusal schemes proved to be reliable and protective for the immediately loaded miniimplants prognosis to support and retain mandibular overdentures. However, the MO scheme yields more favorable PTVs denoting that it offers a better environment for mini-implant osseo-integration.

2- More ridge keratinization occurs in case of MO scheme compared to the LO scheme.

3- There is an inverse relation between EMG records and PTVs and between PTVs of the miniimplants anteriorly and $\mathrm{KI}$ of the ridge posteriorly.

4- Whenever possible, the MO concept should be adopted in cases of immediately loaded miniimplants supporting the mandibular overdentures rather than the LO concept.

KEYWORDS: Overdenture, mini-implants, immediate loading, lingualized occlusion, monoplane occlusion, electromyography, cytological study, keratinization index, periotest.

\section{INTRODUCTION}

The state of complete edentulism is considered the most debilitating condition of old age. (1) Mandibular, rather than maxillary, conventional complete dentures constitute a definite challenging situation to the prosthodontists due to the reduced foundation volume, tongue activity and the accumulation of saliva. ${ }^{(2,3)}$

In a study carried out on 104 patients wearing complete dentures, it was reported that around $80 \%$ of the patients found difficulty with speech and $63 \%$ reported discomfort and instability of the mandibular denture only. Fifty percent avoided several food types and around $17 \%$ reported that they eat easier without the lower denture or even they do not use it. ${ }^{(4)}$

With the increasing success of implant treatment together with the advent of new technologies, narrow diameter (midi and mini) implants are now available to be used to improve patients' tolerance to conventional complete lower dentures specially in cases of narrow alveolar ridges. ${ }^{(5)}$

Advantages of the mini-implants involve the conservative trans-mucosal surgical procedure with decreased initial bone resorption, reduced bleeding, shortened healing time and postoperative discomfort as well as reduced infection possibility during the surgical procedures. ${ }^{(6,7)}$

Different loading protocols are adopted following implant placement considering the biomechanical aspects of the osseo-integrating implants together with the pattern of occlusal loading. The immediate functional loading protocol was the most challenging one as it permits the restoration to occlude against the opposing dentition within 1 to 7 days of implant installation. ${ }^{(8)}$

Immediately loaded mini-implants proved to be a reliable and predictable line of treatment as they offer a simple, less traumatic, affordable and rapid restoration of esthetics, mastication and phonetic qualities of the patient. ${ }^{(9)}$

Different occlusal schemes were tried to choose the most protective one upon the immediately loaded implants supported mandibular overdentures. It was found that the lingualized and monoplane occlusal (LO and MO) schemes were the most protective ones regarding implant prognosis. ${ }^{(10)}$

The occlusal scheme in complete dentures is one of the factors that affects patients' masticatory efficiency. ${ }^{(1)}$ Many authors monitored electromyo- 
graphic (EMG) records and considered them to be an efficient way to evaluate muscle activity. ${ }^{(12,13.14)}$

The choice of an occlusal scheme will determine the pattern of occlusal contacts. The quantity and the intensity of these contacts determine the amount of the forces that are transmitted through the denture bases to the residual ridges ${ }^{(15)}$, thus affecting the ridge keratinization reaction. Keratinization of the alveolar ridge mucosa could result from ordinary denture support, mechanical irritation of the dentures, accumulation of microbial plaque on dentures or occasionally a toxic or allergic reaction to denture base materials. ${ }^{(16,17)}$ Increased keratinization following the wearing of dentures for three months was observed and it was concluded that dentures appeared to stimulate keratinization. ${ }^{(18,19)}$

The periotest is an electrically driven and electronically monitored pressure sensitive taping head impacting the implant 16 times in a horizontal plane (parallel to the floor). Each periotest recording takes approximately 4 seconds with high periotest values (PTVs) denoting loose mini-implants, while those showing proper initial or final bony anchorage yield low PTVs. It was generally accepted that PTVs of (-8 to 9) were considered indicative for satisfactory bone anchorage whether it is due to primary mechanical stability or biological osseointegration. ${ }^{(9)}$ Many authors adopted the use of PTVs to determine the degree of osseo-integration and implant stability. ${ }^{(20,21,22)}$

Reviewing the dental literature, many studies were directed to evaluate the degree of masticatory muscle activity without correlating it with the response of the overdenture supporting structures (ridge keratinization reaction and mini-implant stability). Therefore, this study was conducted to evaluate masseter muscle activity, ridge keratinization and mini-implant stability under immediately loaded mini-implants supporting mandibular complete overdentures with LO and MO schemes.

\section{MATERIAL AND METHODS}

\section{Patient selection}

Twenty completely edentulous male patients, with age ranging from 42 to 63 years with average age of 52.7 years, were selected from the outpatient Removable Prosthodontics Clinic, Faculty of Oral and Dental Medicine, Cairo University. The selected subjects were free from any local or systemic complaint that may contraindicate dental implant placement and/or osseo-integration. Heavy smokers (more than ten cigarettes per day) and those who reported para functional habits were excluded. All patients showed Angle's class I maxillomandibular relation, normal TMJ functions and normal neuromuscular co-ordination. The nature, outline and objectives of the study were declared to the patients. Those who agreed participation signed an informed consent.

\section{Patient grouping}

The patients were randomly divided into two equal groups. For group I patients, complete upper and lower dentures were constructed following the LO scheme entailing palatal cusps occluding with the opposing widened central fossae (fig.1a). For group II patients, complete upper and lower dentures were constructed with the occlusal table set according to the MO scheme including the neutralization of forces and reduction of inclines (fig.1b).

\section{Denture construction}

Conventional technique for complete denture construction was adopted ${ }^{(9,10)}$ using cross linked acrylic resin teeth (Vitatan cross linked acrylic teeth, Veta, Germany).

In group I patients (LO scheme), setting up of anterior teeth was done considering minimal overbite and sufficient overjet dictated by the esthetic and phonetic qualities together with elimination of anterior interference in centric occluding relation and from centric to any eccentric position. 


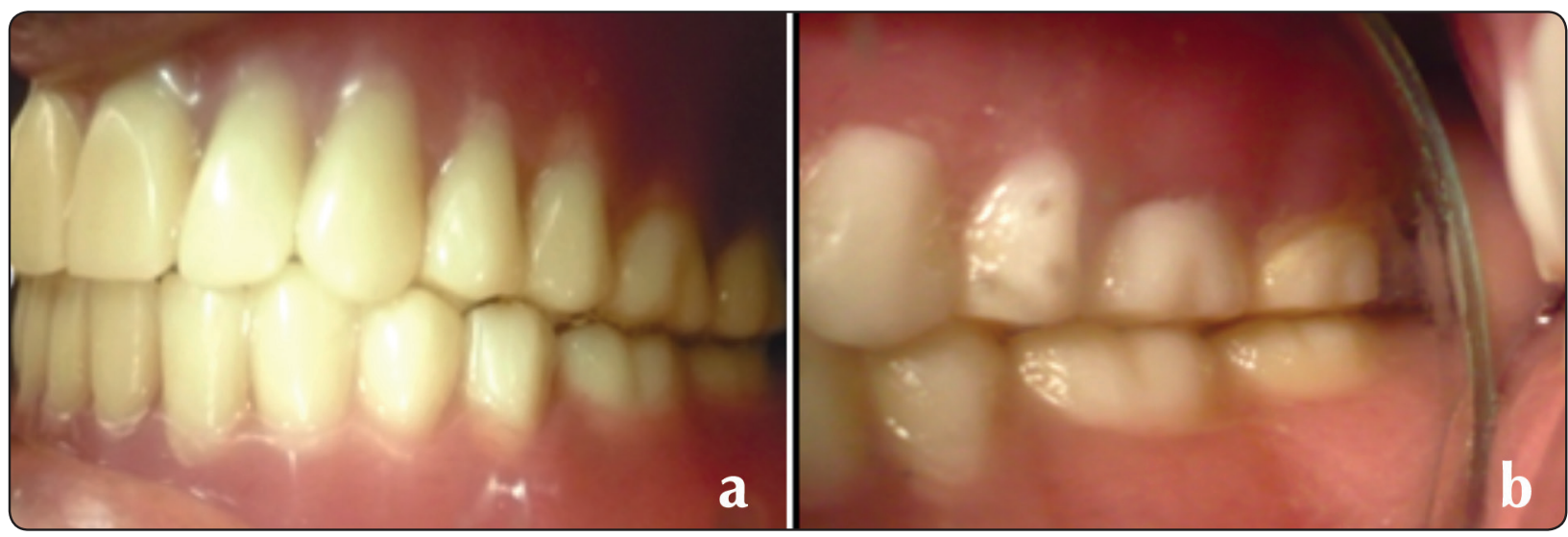

Fig. (1) Upper and lower complete dentures constructed following (a) the LO scheme in group I patients and (b) the MO scheme in group II patients.

The maxillary posterior teeth were modified to eliminate buccal cusp contacts in centric relation and positioned with slight rotation to allow only the palatal cusps to occlude with the opposing widened central fossae of the mandibular posterior teeth that were modified to show reduced buccal and lingual inclines.

For group II patients (MO scheme), setting up of anterior teeth was done with zero overbite relation. The posterior teeth were flattened and arranged antero-posteriorly to be parallel to the denture foundation with no medio-lateral inclination with the second molar being kept out of occlusion.

For both groups, the maxillary and mandibular trial denture bases were tried in the patients' mouths. After performing all the necessary esthetic and occlusal adjustments, dentures were processed in the conventional way using high impact cross linked heat cured acrylic resin (Acrostone heat cured cross linked denture base, England). Dentures were finished, polished, delivered to the patients and inspected after delivery for carrying out the needed occlusal and extension adjustments.

\section{Patient preparation}

For each patient the lower denture was duplicated in clear acrylic resin having amalgam material in the fitting surface of the template opposite the intended implant sites. Diagnostic cone beam tomography was done for each patient wearing the clear template denture in place. Chlorhexidine mouth wash was started one day before the surgery, three times daily, for one week. Anti-inflammatory tablets (Cataflam $50 \mathrm{mg}$ ) were prescribed to the patients 2 hours before the surgery and TDS for 3 days after surgery. An umbrella of antibiotics (Augmentin $625 \mathrm{mg}$ ) was prescribed for the patients 24 hours before the surgery to be continued for one week after surgery on TDS basis to reduce the possibility of infection.

\section{Surgical procedures}

Modification of the clear radiographic template was done to be used as a surgical stent to localize the optimum sites of the 4 mini-implants (OsteoCare ${ }^{\mathrm{TM}}$ Implant system Ltd. Berkshire, UK). A drill of 1.6 $\mathrm{mm}$ diameter and $10 \mathrm{~mm}$ length was used to prepare four flapless osteotomy sites under profound irrigation after field block anaesthesia. During preparation of the osteotomies, a minimum of $5 \mathrm{~mm}$ mesiodistal distance was kept between adjacent mini-implants. Paralleling tools were used to ensure parallelism of the mini-implant recipient sites. Four mini-implants (2.8mm diameter and $13 \mathrm{~mm}$ length) were installed in each patient (fig.2) using the adjustable torque ratchet to thread the mini-implants to their full length and to confirm that the initial 
stability was more than $40 \mathrm{~N} / \mathrm{cm}$ as recommended for immediate loading. Patients were instructed to strictly follow the prescribed medications, soft diet and proper oral hygiene measures.

\section{Pick up procedures and denture delivery}

After 2 days, the polycarbonate housing caps (OsteoCare $^{\mathrm{TM}}$ Implant System Ltd. Berkshire, UK) containing the rubber $\mathrm{O}$ rings were snapped on the ball head mini-implants. Sufficient relief was created on the tissue surface of the lower denture opposite to the 4 mini-implants with lingual escaping holes. Block out of the ball head implant undercut was performed using punched rubber dam. Self curing acrylic resin was applied opposite to the 4 mini-implant sites. The mandibular and maxillary dentures were reseated in the patient's mouth to ensure complete non interfered seating during polymerization. After complete polymerization, the mandibular overdenture was removed from the patient's mouth having the rubber $\mathrm{O}$ rings contained within the housing caps. (fig.3) The denture was inspected and the excess resin was removed and smoothened. The occlusal contacts were finally verified and adjusted if required. Dentures were then delivered to the patients after motivation for proper oral and denture hygiene.

\section{Recording the EMG activity}

EMG activity of the masseter muscle of both sides was recorded using the key point electromyogram (Alpine Biomed, USA).The data was expressed as root mean square (RMS) values in micro voltage (mv). The records were done after the patient was seated in an upright relaxed position (fig.4). The area of the masseter muscle greatest activity was first located by asking the patient to clench. A point $1 \mathrm{~cm}$ behind the area of the palpated anterior border of the greatest lateral distension parallel to the main fiber direction was marked. Transparent celluloid plastic sheet was used as a template to ensure exact repositioning of the EMG electrodes

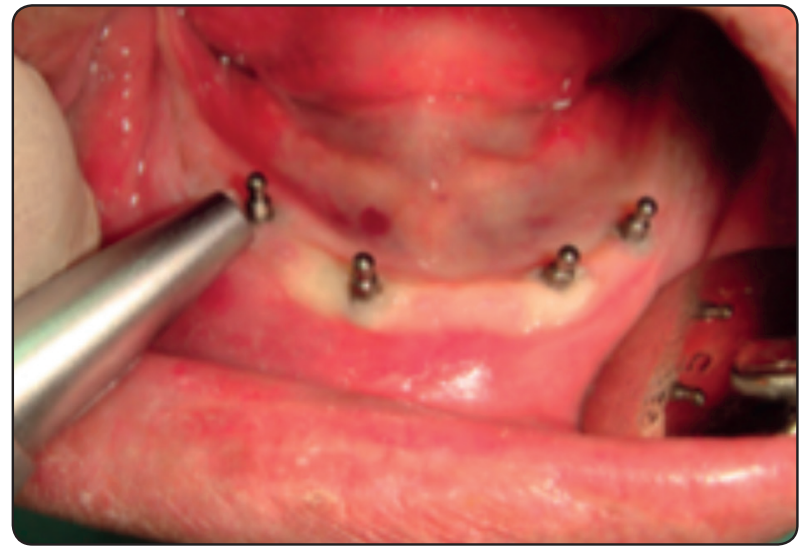

Fig. (2) The 4 ball head mini-implants in place with the Periotest $\mathrm{M}$ device used to assess their stability.

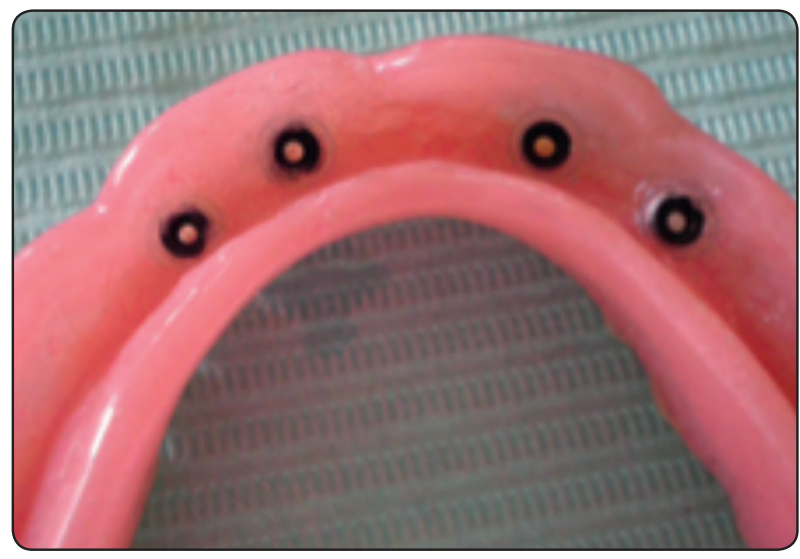

Fig. (3) The polycarbonate housing containing the rubber $\mathrm{O}$ rings picked up in the mandibular ovedenture.

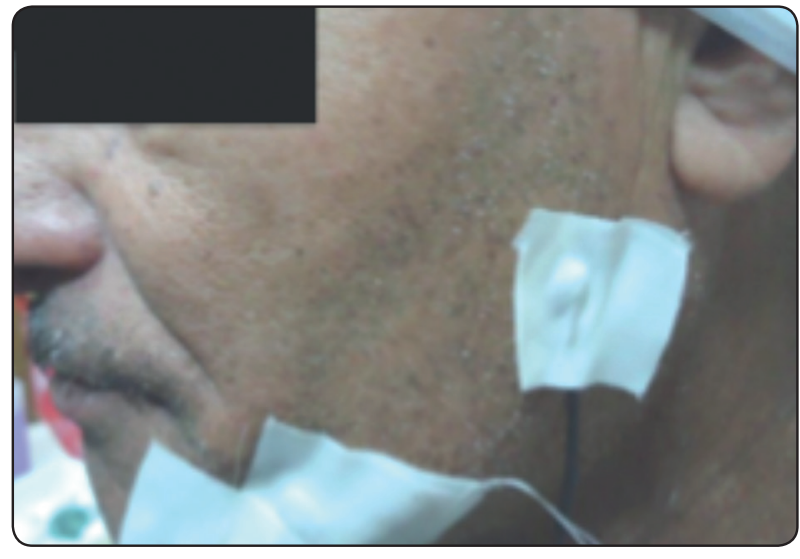

Fig. (4) Recording RMS values of the EMG records of the masseter muscle. 
during the successive follow up records of the same patient. ${ }^{(23,14)}$ The records were done using $1 \mathrm{~cm}^{3}$ cubes of hard type of food (carrots) at the time of denture delivery, 1 month and 4 months after denture delivery for group I and II patients. The mean RMS records of the right and left masseter muscles for each patient were calculated.

\section{Exfoliative cytology}

The degree of keratinization of the residual ridge mucosa was cytologically investigated. The investigation area was swabbed by a cotton pellet. Cytological smears were collected gently using a metal spatula and spread widely over glass slides to be fixed immediately using absolute ethyl alcohol for 30 minutes and stained with PAP stain. ${ }^{(24)}$ Two cytological smears were collected from each patient from the mid crestal area of the residual alveolar ridge mucosa of the lower first-second molar region bilaterally at the time of denture delivery, 1 and 4 months after denture delivery.

Cytological examination of the PAP stained slides was carried out under the bright field light microscopy. An initial screening at magnification of x100 was made to choose the most appropriate cell rich fields. Further examination was done at magnification of $\mathrm{x} 400$ to detect the keratinized cells. PAP stained superficial keratinized cells were stained orange to brown, while the parabasal cells were stained faint green-blue and the intermediate cells were stained pink.

The image analyser computer system using the software Leica Quin 500 (Leica Microsystems, Wetzlar GmbH, DM LB2/11888111, Germany) was used to measure the area percent of the orange to brown stained cells representing the keratinized cells in relation to the total epithelial cell population. The orange to brown stained cells were chosen for evaluation in a standard measuring frame using a magnification of $x 400$ by light microscopy transferred to the monitor's screen. These cells were masked by a green color using the computer analysis system. Area percent values of keratinized cells for each slide were obtained from 3 different fields. ${ }^{(25)}$ The mean values of the right and left alveolar ridge mucosa for each patient were calculated.

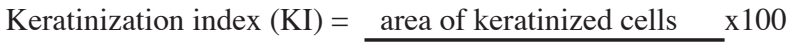
area of total cell population

\section{Periotest measurements}

Assessment of the mini-implants' stability was done by the Periotest $\mathrm{M}$ device (Medizintechnik Gulden e.K.Modautal/Germany) (fig.2). This was done with the periotest tapping head held parallel to the floor approximating the mini-implant for at least $4 \mathrm{sec}$. for each reading ${ }^{(9)}$. The average of 3 successive PTVs was obtained for each miniimplant at each follow up period. The readings were collected at the time of denture delivery, 1 and 4 months after denture delivery.

\section{Statistical analysis}

The EMG records, KI values and PTVs were statistically analysed (Statistical Software Package $\mathrm{R}$ version 2.15.2(26-10-2010) using One Way Analysis of Variance (ANOVA) test to compare the three follow up periods of the two denture occlusal schemes followed by Tukey test for pairwise comparisons between each two groups. Student T-test was used to compare the change in values between LO and MO after 1 and 4 months. Pearson's correlation test was used to correlate the change in EMG records, KI values and PTVs after 4 months of denture delivery. Median values for the collected data were chosen for statistical analysis due to lack of normal data distribution.

\section{RESULTS}

\section{Results of EMG}

As shown in table (1) and fig. (6A), the median EMG values for LO and MO groups showed a continuous increase along the follow up periods 
TABLE (1): Median values for EMG records along the follow up period in LO \& MO groups.

\begin{tabular}{|l|c|c|c|c|}
\hline \multirow{2}{*}{ Study groups } & EMG at denture delivery & EMG after 1 month & EMG after 4 months & \multirow{2}{*}{ P value for time effect } \\
\cline { 2 - 5 } & Median (range) & Median (range) & Median (range) & \\
\hline LO & $0.76(0.60-0.93) \mathbf{c}$ & $0.99(0.83-1.38) \mathbf{b}$ & $1.18(0.92-1.64) \mathbf{a}$ & $<0.001$ \\
\hline MO & $1.01(0.84-1.42) \mathbf{c}$ & $1.31(0.99-1.65) \mathbf{b}$ & $1.55(1.29-2.22) \mathbf{a}$ & $<0.001$ \\
\hline
\end{tabular}

$* P$ value is significant $\leq 0.05$, time point sharing the same letter are not significantly different

with a statistically significant $(\mathrm{P}<0.001)$ increase from the time of denture delivery (0.76 and 1.01, respectively) to 1 month ( 0.99 and 1.31 , respectively) and to 4 months (1.18 and 1.55 , respectively) after denture delivery.

As shown in table (2) and fig. (6A), the absolute change of the median EMG values of the LO group was not statistically significant than the MO group after 1 month ( 0.3 and 0.24 , respectively) and after 4 months ( 0.42 and 0.55 , respectively) after denture delivery $(\mathrm{P}=0.32$ and $\mathrm{P}=0.17$, respectively).

TABLE (2) Change in median values for EMG records after 1 and 4 months in LO \& MO groups.

\begin{tabular}{|l|c|c|}
\hline \multirow{2}{*}{$\begin{array}{l}\text { Study } \\
\text { groups }\end{array}$} & $\begin{array}{c}\text { EMG change after 1 } \\
\text { month }\end{array}$ & $\begin{array}{c}\text { EMG change after 4 } \\
\text { months }\end{array}$ \\
\cline { 2 - 3 } & Median (range) & Median (range) \\
\hline LO & $0.30(0.10-0.48)$ & $0.42(0.25-0.71)$ \\
\hline MO & $0.24(0.15-0.38)$ & $0.55(0.41-0.91)$ \\
\hline p value & 0.32 & 0.17 \\
\hline
\end{tabular}

$* P$ value is significant $\leq 0.05$

\section{Results of cytological examination and KI}

Microscopic examination of PAP stained cytological smears collected from the ridge mucosa at time of denture delivery for LO and MO groups showed nucleated faint blue to green stained parabasal cells and intermediate pink stained cells as well as few superficial keratinized cells which were stained orange to brown (figs. $5 \mathrm{a} \& \mathrm{~b}$ ). Keratinization increased obviously along the follow up period in both groups to show numerous brown to orange stained cells after 4 months of denture delivery (figs. 5 c \& d).

As shown in table (3) and fig. (6B), the median KI values for $\mathrm{LO}$ and MO groups showed a continuous increase along the follow up periods with a statistically significant $(\mathrm{P}<0.001)$ increase from the time of denture delivery (43.26 and 38.15 , respectively) to 1 month (54.38 and 55.31, respectively) and to 4 months (57.89 and 60.72, respectively) after denture delivery.

As shown in table (4) and fig. (6B), the absolute change of the median KI values of the MO group was statistically significant than the LO group after 1 month (16.61 and 9.84, respectively) and after 4 months (22.87 and 14.23, respectively) after denture delivery ( $\mathrm{P}=0.002$ and $\mathrm{P}<0.001$, respectively). 


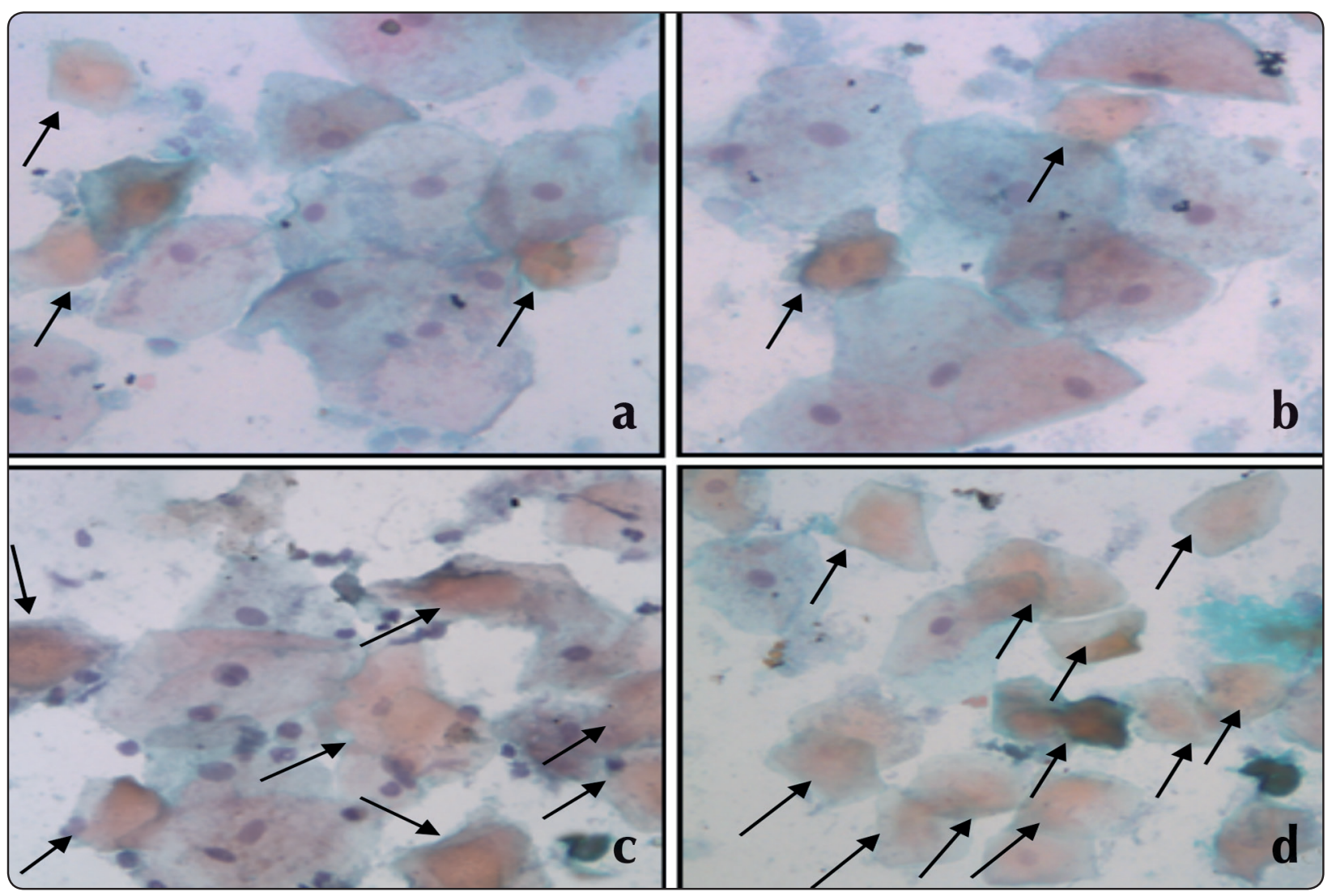

Fig. (5) Photomicrographs showing few keratinizing cells (arrows) at time of denture delivery for (a) LO and (b) MO groups and numerous keratinizing cells (arrows) after 4 months of denture delivery for (c) LO and (d) MO groups (PAPx400).

TABLE (3) Median values for KI along the follow up period in LO \& MO groups.

\begin{tabular}{|c|c|c|c|c|}
\hline \multirow{2}{*}{ Study groups } & KI at denture delivery & KI after 1 month & KI after 4 months & \multirow{2}{*}{$\begin{array}{c}\text { P value for time } \\
\text { effect }\end{array}$} \\
\cline { 2 - 5 } & Median (range) & Median (range) & Median (range) & $<0.001$ \\
\hline LO & $43.26(23.32-63.64) \mathbf{c}$ & $54.38(28.82-80.19) \mathbf{b}$ & $57.89(31.84-84.31) \mathbf{a}$ & $<0.001$ \\
\hline
\end{tabular}

$* P$ value is significant $\leq 0.05$, time point sharing the same letter are not significantly different

TABLE (4) Change in median values for KI after 1and 4 months in LO \& MO groups.

\begin{tabular}{|l|c|c|}
\hline \multirow{2}{*}{$\begin{array}{l}\text { Study } \\
\text { groups }\end{array}$} & $\begin{array}{c}\text { KI change after } 1 \\
\text { month }\end{array}$ & $\begin{array}{c}\text { KI change after } 4 \\
\text { months }\end{array}$ \\
\cline { 2 - 3 } & Median (range) & Median (range) \\
\hline LO & $9.84(5.49-16.55)$ & $14.23(8.52-20.67)$ \\
\hline MO & $16.61(10.95-26.46)$ & $22.87(19.88-31.38)$ \\
\hline p value & 0.002 & $<0.001$ \\
\hline
\end{tabular}

*P value is significant $\leq 0.05$

\section{Results of periotest}

As shown in table (5) and fig. (6C), the median PTVs for LO group showed a continuous increase along the follow up period with a statistically significant $(\mathrm{P}=0.002)$ increase only after 1 month (0.765) compared to the time of denture delivery (0.075) with no further significant increase after 4 months. As regards the MO group, there was a statistically significant perculating pattern 
$(\mathrm{P}<0.001)$ in median PTVs manifested as a subsequent statistically significant drop after 4 statistically significant increase after 1 month $(0.15)$ months $(-0.15)$ than one month $(0.15)$ from denture than at the time of denture delivery $(-0.005)$ with delivery to reach values less than those at time of TABLE (5) Median PTVs along the follow up period in LO \& MO groups.

\begin{tabular}{|c|c|c|c|c|}
\hline \multirow{2}{*}{ Study groups } & PTV at denture delivery & PTV after 1 month & PTV after 4 months & \multirow{2}{*}{ P value for time effect } \\
\cline { 2 - 5 } & Median (range) & Median (range) & Median (range) & 0.002 \\
\hline LO & $0.075(-5.39-4.66) \mathbf{b}$ & $0.765(-5.03-7.03) \mathbf{a}$ & $0.785(-4.91-5.98) \mathrm{a}$ & $<0.001$ \\
\hline MO & $-0.005(-5.44-4.76) \mathbf{b}$ & $0.15(-4.23-6.07) \mathbf{a}$ & $-0.15(-6.83-3.55) \mathbf{c}$ & $<$ \\
\hline
\end{tabular}

*P value is significant $\leq 0.05$, time point sharing the same letter are not significantly different

TABLE (6) Change in median PTVs after 1 and 4 months in LO \& MO groups.

\begin{tabular}{|c|c|c|}
\hline \multirow{2}{*}{ Study groups } & PTV change after 1 month & PTV change after 4 months \\
\cline { 2 - 3 } & Median (range) & Median (range) \\
\hline LO & $1.42(-0.35-4.96)$ & $0.95(0.25-3.91)$ \\
MO & $0.61(0.11-1.31)$ & $-0.58(-1.39--0.12)$ \\
p value & 0.17 & $<0.001$ \\
\hline
\end{tabular}

*P value is significant $\leq 0.05$

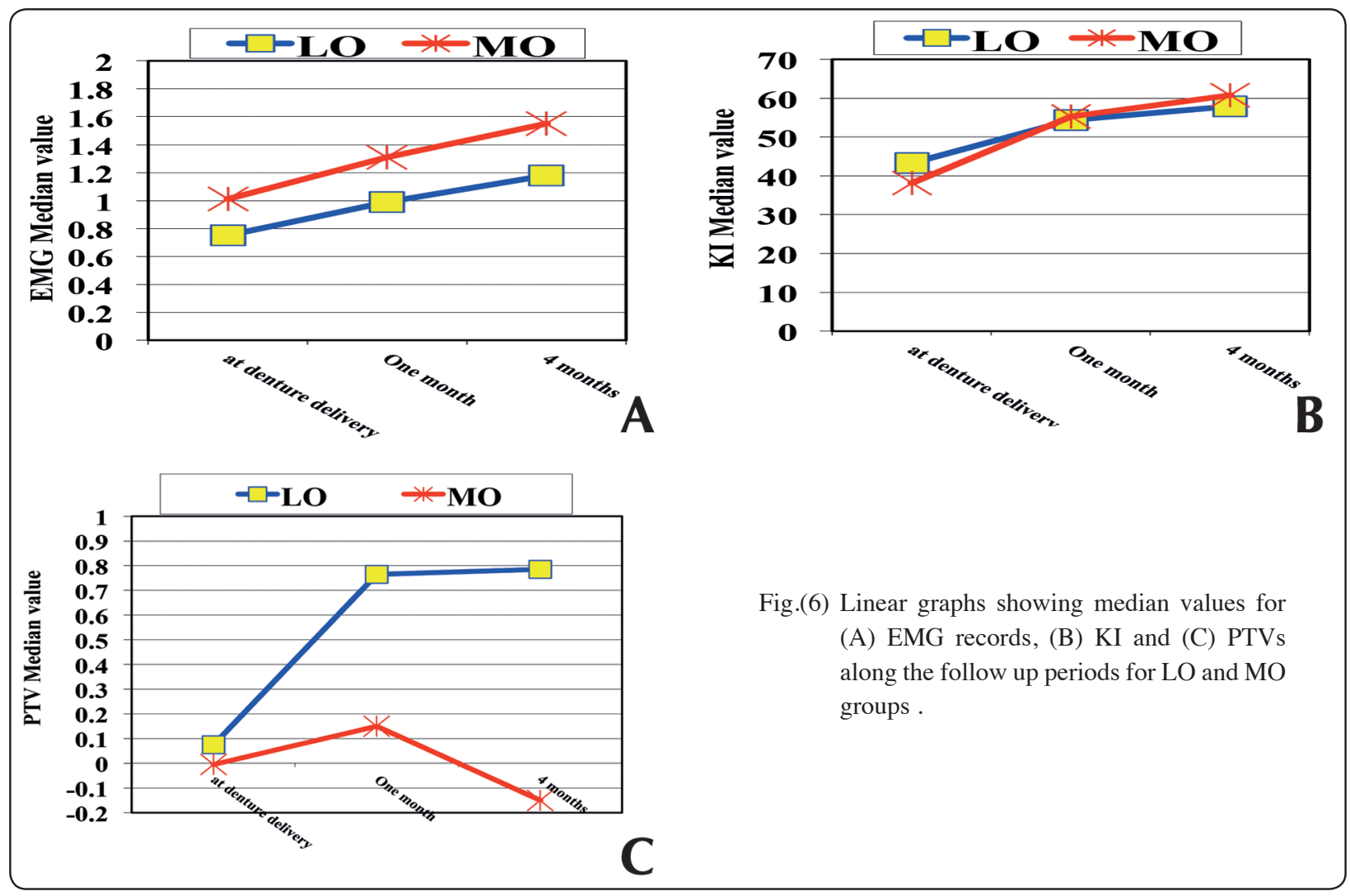


denture delivery (-0.005).

As shown in table (6) and fig. (6C), the absolute change of the median PTVs of the LO group was statistically insignificant $(\mathrm{P}=0.17)$ than $\mathrm{MO}$ group after 1 month (1.42 and 0.61 , respectively) in comparison to the statistically significant $(\mathrm{P}<0.001)$ results after 4 months ( 0.95 and -0.58 , respectively).

\section{Correlation test}

Pearson correlation test showed a statistically significant $(\mathrm{P}<0.05)$ inversely correlated relation between median change of EMG values and PTVs and no significant correlation $(\mathrm{p}=0.096)$ between EMG and KI values after 4 months of denture delivery. However, a statistically significant $(\mathrm{P}<0.01)$ correlation between the median change of PTVs and KI values was noticed after 4 months of denture delivery (table 7).

TABLE (7): Correlation between median changes in EMG records, KI values and PTVs after 4 months.

\begin{tabular}{|c|c|c|c|c|}
\hline & & $\begin{array}{l}\text { EMG. } \\
\text { ch4m }\end{array}$ & $\begin{array}{c}\text { PTV } \\
\text { change } \\
\text { after } 4 \\
\text { months }\end{array}$ & KI.ch4m \\
\hline \multirow[t]{3}{*}{$\begin{array}{l}\text { EMG. } \\
\text { ch4m }\end{array}$} & $\begin{array}{l}\text { Pearson } \\
\text { Correlation }\end{array}$ & 1 & $-.497(*)$ & .383 \\
\hline & Sig. (2-tailed) & . & .026 & .096 \\
\hline & $\mathrm{N}$ & 20 & 20 & 20 \\
\hline \multirow{3}{*}{$\begin{array}{l}\text { PTV } \\
\text { change } \\
\text { after } 4 \\
\text { months }\end{array}$} & $\begin{array}{l}\text { Pearson } \\
\text { Correlation }\end{array}$ & $-.497(*)$ & 1 & $-.580(* *)$ \\
\hline & Sig. (2-tailed) & .026 & . & .007 \\
\hline & $\mathrm{N}$ & 20 & 20 & 20 \\
\hline \multirow[t]{3}{*}{ KI.ch4m } & $\begin{array}{l}\text { Pearson } \\
\text { Correlation }\end{array}$ & .383 & $-.580(* *)$ & 1 \\
\hline & Sig. (2-tailed) & .096 & .007 & \\
\hline & $\mathrm{N}$ & 20 & 20 & 20 \\
\hline
\end{tabular}

* Correlation is significant at the 0.05 level (2-tailed).

** Correlation is significant at the 0.01 level (2-tailed).

\section{DISCUSSION}

The use of the simple flapless low cost miniimplants to support and retain mandibular overdentures improves the patients quality of life. This treatment allows immediate comfortable chewing upon a more stable and retentive mandibular overdenture than in case of conventional complete dentures. ${ }^{(26,27)}$

The protective effect of both the lingualized and monoplane occlusal concepts upon the supporting mini-implants ${ }^{(10)}$ is the reason for comparing between them so as to determine which occlusal concept is able to yield more favorable functional muscle activity, ridge keratinization response posteriorly together with favorable mini-implant osseo-integration anteriorly.

Considering the accuracy of the study results, female patients were excluded to avoid the consequences of post menopausal hormonal changes upon the ridge mucosal keratinization ${ }^{(28)}$, and also upon the osseo-integration of the healing implants ${ }^{(29,30)}$, together with the documented marked difference of muscle action between the larger bulk of the masseter muscle fibers in males rather than females ${ }^{(31)}$

The use of mini-implants to support mandibular overdentures is usually suitable for thin atrophic lower ridges (less than $5 \mathrm{~mm}$ labio-lingual dimension) that usually constitutes a definite problematic situation for the prosthodontists to reach adequate prognosis if treated with conventional complete mandibular dentures or using normal diameter implant retained mandibular overdentures..$^{(32,33,27)}$

Four mini-implants were used in this study as they exceed the bone implant contact (BIC) of the reported adequate prognosis of two immediately loaded standard sized implants ${ }^{(34)}$. This has an added advantage of better arch distribution of the four mini-implants that offers better resistance to leverage force. ${ }^{(35)}$ 
In this study, the auto-advancement (selfthreading) insertion pattern of the used miniimplants allowed them to have sufficient initial mechanical integration to be immediately loaded due to the more compacted BIC that was verified by the adjustable torque wrench not to be less than $40 \mathrm{~N} / \mathrm{cm}^{2}$. These mini-implants, also, were reported to have sufficient retentive qualities as their pull out resistance is more dependent on their length rather than their diameter ${ }^{(36)}$. These mini-implants, thus, integrate well after immediate functional loading giving satisfactory long term prognosis. ${ }^{(37,38,39)}$

Masseter muscle was chosen for representing muscle activity since it is the largest and strongest pure closing masticatory muscle. It also plays a major role in mandibular movement. ${ }^{(40)}$ Its efficiency was measured using the EMG. Hard food was used in the EMG test (cubes of carrots) as it induces more obvious changes in muscle activity than soft food. ${ }^{(41)}$ The RMS values were used to evaluate the EMG changes in this study due to their documented accuracy. ${ }^{(23,42)}$.

Statistical management of the EMG, KI and PTVs data was carried out using the median values to yield more accurate results as the data was not normally distributed. The use of the median values of EMG, KI and PTVs also allowed for statistical correlations between the various tested parameters.

In this study there was an initial significant increase in median EMG values after one month than at time of denture delivery for both denture groups. This was in accordance with Risk (2014) ${ }^{(14)}$ who reported an improvement in EMG records in the first follow up period. By time, however, a more confident patient performance using the overdentures was achieved after 4 months of denture delivery, thus yielding a significant continuous increase in EMG records than at the time of denture delivery in both denture groups. This was in accordance with Scepanvic et al. (2012) ${ }^{(43)}$ and Ashmawy et al. (2015) ${ }^{(41)}$ who reported definite improvement in chewing ability and mean EMG values of the patients using four mini-implants retained mandibular overdentures upon longer durations of use (more than one month of denture delivery).

In this study, there was an insignificant difference between the LO and MO groups as regards the median changes (increase) of the EMG values after 1 and 4 months of denture use. This might be explained by the favorable occlusal load distribution offered by both occlusal schemes upon the miniimplants and the ridge supporting the mandibular overdentures. ${ }^{(10,14)}$

As regards the KI, there was a significant continuous increase in the degree of keratinization from the time of denture delivery to 1 and 4 months after denture delivery for both denture groups. This was in accordance to Jani and Bhargava (1976) (44) who conducted a biopsy examination for the thickness of the keratin layer of the palatal mucosa supporting complete dentures after three months of denture delivery and found a significant increase in keratin layer thickness. This was also in agreement with Mneizel (2003) ${ }^{(28)}$ who reported an increased thickness of the keratin layer of the palatal mucosa after 1 month of acrylic complete denture delivery. The results of this study could be explained by the adaptive protective ridge mucosal reaction in the form of increased ridge keratinization to positively support the mandibular overdenture posteriorly which was directly subjected to the masticatory forces in both denture groups.

This explanation was also supported by a study conducted by Aziz and Amin (2015) ${ }^{(45)}$ who reported a decrease in ridge keratinization after six months of denture use than at the time of denture delivery. This reduction in ridge keratinization was due to keeping the examined anterior partial dentures completely out of occlusion in centric occluding relation as well as from centric to any other eccentric position.

The results of this study showed a significant change (increase) in the KI after 4 months in the 
MO group in comparison to the LO group. This might be related to the increased EMG activity of the $\mathrm{MO}$ group rather than that of the $\mathrm{LO}$ group. This might be explained on the basis of the less efficient non anatomical occlusal form in the MO group with subsequent need for more occlusal force, hence resulting in more protective ridge keratinization reaction. ${ }^{(24,23,14)}$

As regards the PTVs, this study showed a significant increase in the median PTVs from the time of denture delivery to 1 month after denture delivery in both denture groups. This was in accordance to Beyari (2014) ${ }^{(46)}$ who revealed significant increase in PTVs in case of two mini-implants supported mandibular overdenture throughout the study period. The author clarified that there was no harm as the increase in the PTVs was within the documented acceptable range (-8 to 9 ) considering that he used only two mini-implants to immediately support and retain a mandibular overdenture.

The significant decrease in median PTVs observed in the present study from the time of denture delivery to 4 months of denture delivery in the MO group indicates that the MO scheme offers a better environment for the mini-implants to biologically osseo-integrate rather than the LO scheme. This might be explained by the reduction of the cusp inclines in MO group that prevents the harmful lateral forces that might adversely affect the healing of the mini-implants. This was contrary to the findings of Beyari (2014) ${ }^{(46)}$ who reported a statistically significant increase in the PTVs throughout the study period. The results of the author can be explained on the basis of the limited number (only two) of the used mini-impants to immediately support and retain the mandibular overdenture. The author, also, did not consider the effect of the used occlusion scheme so as to allow for a protective environment for the healing miniimplants that immediately support and retain the mandibular overdentures.
The insignificant difference in the absolute changes of PTVs after 1 month between LO and MO groups may be attributed to some contributing factors such as proper case selection with satisfactory bone quality as confirmed radiographically, thorough oral hygiene during the study period and the opposing complete denture that exerts less forces upon the mandibular overdenture as compared to fixed restorations or even natural dentition ${ }^{(47)}$.

The results of this study revealed significant inversely proportional relation between the change in median values of EMG records and the PTVs after 4 months i.e the lower median PTVs (favorably integrated mini-implants), the higher the EMG values. This might be explained as the patient becomes more comfortably chewing upon the prosthesis when it is supported and retained by adequately anchored mini-implants and vice versa i.e low grade mini-implants integration to the jaw bone will subsequently lead to decreased muscle functions as a result of uncomfortable chewing upon inadequately anchored mini-implants. This was in accordance with Heckmann et al. (2009) ${ }^{(48)}$ who declared that improvement in implant stabilization is accompanied by an immediate increase in the neuromuscular parameters. This was further explained by DeRossi et al. (2014) ${ }^{(47)}$ who stated that the bone in the peri implant regions contains nerve fibers which may serve as a source of sensory feedback instead of the periodontal ligament. This physiologic mechanism of osseoperception is supposed to be the cause for the obvious negative correlation between the decreased PTVs of the mini-implants and the increased EMG values denoting improved masticatory functions secondary to properly anchored mini-implants.

The results of this study revealed no significant correlation between the EMG values and the degree of keratinization of the ridge mucosa. This was discussed by Aziz and Amin ${ }^{(45)}$ who reported that 
the ridge keratinization is not a simple mucosal reaction to loading, but it has many types and causes. It could be either mainly orthokeratinized which results mainly from loading and/or frictional effects of the denture tissue surface against the ridge mucosa or mainly parakeratinzed that results mainly from microorganisms and bacterial colonization on the tissue surface of the removable prosthesis.

This could also be explained on the basis of the combined mini-implants-ridge supported mandibular overdenture that were used in this study, so that the residual ridge is not supporting the prosthesis alone, but the mini-implants as well. Thus, the ridge keratinization reaction is subsequently affected by the anterior mini-implants stability. This explanation was also supported by the results of this study concerning the inverse correlation between the KI of the residual ridge and PTVs of the anterior mini-implants. This correlation confirms that the better anchored anterior mini-implants, the more keratinization of the residual ridge posteriorly as an adaptive and protective mechanism of the ridge to withstand the more confident patient chewing upon the properly anchored anterior mini-implants supporting the mandibular overdentures.

\section{CONCLUSIONS}

From the results of this study it could be concluded that:

1- Both occlusal schemes proved to be reliable and protective for the stability of the immediately loaded mini-implants that support and retain mandibular overdentures.

2- MO scheme yields more favorable PTVs denoting that it offers a better environment for mini-implant osseo-integration than the LO scheme.

3- There is an inverse relation between EMG activity and the PTVs of the mini-implants.
4- There is an inverse relation between KI of the ridge posteriorly and the PTVs of the anterior mini-implants supporting the mandibular overdentures.

\section{RECOMMENDATION}

Whenever possible, MO concept should be adopted in cases of immediately loaded miniimplants to support and retain the mandibular overdenture rather than the LO concept.

\section{REFERENCES}

1- Christensen GJ: Treatment of the edentulous mandible. J. Am. Dent. Assoc., 132 (2):231-233, 2001.

2- Doundoulakis JH, Eckert SE, Lindquist CC, Jeffcoat MK: The implant-supported overdenture as an alternative to the complete mandibular denture. J. Am. Dent. Assoc., 134(11):1455-1458, 2003.

3- Misch CE: Dental implant prosthetic's. Mosby Inc. St. Louis, pp.211, 223, 2005.

4- Misch LS, Misch CE: Denture satisfaction: A patient's prospective. Int. J.Oral Implantol., 7:43-49,1991.

5- Vigolo P, Givani A: Clinical evaluation of single-tooth mini-implant restorations: a five-year retrospective study. J. Prosthet. Dent., 84(1):50-54, 2000.

6- Gibney J: Minimally invasive implant surgery. J. Oral Implantol., 27:73-76, 2001.

7- Campelo LD, Camara JR: Flapless implant surgery: a 10year clinical retrospective analysis. Int. J. Oral Maxillofac. Implants, 17(2):271-276, 2002.

8- Aparicio C, Rangert B, Sennerby L: Immediate/early loading of dental implants: a report from the Sociedad Española de Implantes World Congress consensus meeting in Barcelona, Spain, 2002. Clin. Implant Dent. Relat. Res., 5(1):57-60, 2003.

9- Abd-El-Wahab KA: The effect of two loading protocols on the supporting structures of mini-implants supporting mandibular overdenture. PHD thesis, Removable Prosthodontics, Faculty of Oral and Dental Medicine, Cairo University, 2011.

10- Elawady AFF, Aziz EA, Swelem AA, El-Zawahry M: Bone reaction around early-loaded mini-implants supporting mandibular overdentures with different protective occlusal schemes. J. Am.Sc., 7(11): 20-28, 2011. 
11- Ahmed AR, Muneer MU, Hakeem S: Masticatory efficiency between balanced and lingualized occlusion in complete denture wearers. Pakistan Oral and Dent. J., 33(1): 200-206, 2013

12- Nuño LA, Angeles MF, Pacheco SME, Sarabia VA, García MC: Electromyographic activity (EMG) of masseter and temporal muscles in edentulous patients before and after complete dentures. Pract. Odontol., 11(8):54-56, 1990.

13- Shah FK, Gebreel A, Elshokouki AH, Habib AA, Porwal A: Comparison of immediate complete denture, tooth and implant-supported overdenture on vertical dimension and muscle activity. J. Adv. Prosthodont., 4:61-71, 2012.

14- Risk FN: Effect of two different attachments on the supporting structures and masticatory capacity of implant retained mandibular overdenture. EDJ, 60:1797-1812, 2014.

15- Tarazi E, Ticotsky-Zadok N: Occlusal schemes of complete dentures--a review of the literature. Refuat Hapeh Vehashinayim (1993), 24(1):56-64, 85-86, 2007.

16- Budtz-Jorgensen E: Oral mucosal lesions associated with the wearing of removable dentures. J. Oral Pathol., 10:6580,1981 .

17- Tolboe H, Isidor F, Budtz-Jörgensen E and Kaaber S: Influence of oral hygiene on the mucosal conditions beneath bridge pontics. Scand. J. Dent. Res., 95(6):475-482, 1987.

18- Kapur K, Shklar G :The effect of complete dentures on alveolar mucosa. J. Prosthet. Dent., 13(6):1030-1037, 1963.

19- Akal UK, Mocan A, Aydoğan S, Oygür T, Bağci L, Camdeviren $\mathrm{H}$ : Keratinization of palatal mucosa beneath metal-based removable partial and acrylic-based complete dentures compared with normal palatal mucosa: a clinical, cytological and histological study. J. Marmara. Univ. Dent. Fac., 2(4):665-672, 1997.

20- Krennmair G, Weinländer M, Krainhöfner M, Piehslinger E: Implant-supported mandibular overdentures retained with ball or telescopic crown attachments: a 3-year prospective study. Int. J. Prosthodont., 19(2):164-170, 2006.

21- Elsyad MA, Gebreel AA., Fouad MM, Elshoukouki AH: The clinical and radiographic outcome of immediately loaded mini implants supporting a mandibular overdenture. A 3-year prospective study. J. Oral Rehabil., 38: 827-834, 2011.
22- Arora V, Kumar D, Legha VS, Arun Kumar KV: Prospective study of treatment outcome of implant retained mandibular overdenture: Two years follow-up. Contemp. Clin. Dent., 5(2): 155-159, 2014.

23- Aziz EA: Electromyographic evaluation of two different implant super structures under mandibular partial overdenture. EDJ, 51: 1965-1972, 2005.

24- Aziz EA: The effect of two designs of interim partial dentures on the gingiva and the supporting mucosal tissues of the residual ridge. M. Sc. thesis, removable prosthodontics, Faculty of Oral and Dental Medicine, Cairo University, 1993

25- Verma R, Singh A, Badni M, Chandra A, Gupta S and Verma R: Evaluation of exfoliative cytology in the diagnosis of oral premalignant and malignant lesions: A cytomorphometric analysis. Dent. Res. J. (Isfahan). 12(1):83-88, 2015.

26- Christensen GJ: www.dentaleconomics.com,2009.

27- Garhnayak M, Garhnayak L, Dev S, Kar AK, Mohapatra A: Prosthodontic management of flat mandibular ridge by mini implant supported over denture. J. Clin. Diagn. Res. , 8(7):ZD19-21, 2014.

28- Mneizel T: A study of the palatal keratinization levels beneath complete acrylic resin dentures. JRMS, 12 (1):25$29,2003$.

29- Tortopidis D, Lyons MF, Baxendale RH, Gilmour WH: The variability of bite force measurement between sessions, in different positions within the dental arch. J. Oral Rehabil., 25(9):681-686, 1998.

30- Hatch JP, Shinkai RS, Sakai S, Rugh JD, Paunovich ED: Determinants of masticatory performance in dentate adults. Arch. Oral Biol., 46(7):641-648, 2001.

31- Shinogaya T, Bakke M, Thomsen CE, Vilmann A, Sodeyama A, Matsumoto M: Effects of ethnicity, gender and age on clenching force and load distribution. Clin. Oral Investig., 5(1):63-68, 2001.

32- Zahran A, Gauld J: Gauld's technique: Clinical innovation of flapless placement of self-tapping implants with the aid of osteotomes in the posterior maxilla. EDJ, 53: 2297 2304, 2007.

33- Zahran A: Clinical evaluation of the osteocare mini and midi implants for immediate loading of mandibular overdentures. Imp. Dent. Today, 2 (1): 54-59, 2008. 
34- Lerner H: Minimal invasive implantology with small diameter implants. Implant Pract., 2(1): 30-35, 2009

35- Englsh CE, Bohle GC: Diagnostic, procedural and clinical issues with the Sendax mini dental implants. Compendium, 24 (1):1-23, 2003.

36- Block MS, Delgado A, Fontenot MG: The effect of diameter and length of hydroxylapatite-coated dental implants on ultimate pullout force in dog alveolar bone. J. Oral Maxillofac. Surg. , 48(2):174-178, 1990.

37- Steele JG: National diet and nutrition survey people aged 65 years and over .The Stationary Office, London,UK, Vol 2: Report of the oral health survey, 1998.

38- Kanie T, Nagata M, Ban S: Comparison of the mechanical properties of 2 prosthetic mini-implants. Implant Dent., 13(3):251-256, 2004.

39- Griffitts TM, Collins CP, Collins PC: Mini dental implants: an adjunct for retention, stability, and comfort for the edentulous patient. Oral Surg. Oral Med. Oral Pathol. Oral Radiol. Endod., 100(5):e81-84, 2005.

40- Eriksson PO, Thornell LE: Histochemical and morphological muscle-fibre characteristics of the human masseter, the medial pterygoid and the temporal muscles. Arch. Oral Biol., 28(9):781-795, 1983.

41- Ashmawy TM, El Talawy DB, Shaheen NH: Effect of mini-implant-supported mandibular overdentures on electromyographic activity of the masseter muscle during chewing of hard and soft food. Quintessence Int. , 45(8):663-671, 2014.
42- Fukuda TY, Echeimberg JO, Pompeu JE, Lucareli PRG, Garcia PR, Garbelotti Junior SA, Gimenes RO, Apolinário A: Root Mean Square Value of the Electromyographic Signal in the Isometric Torque of the Quadriceps, Hamstrings and Brachial Biceps Muscles in Females. Appl. Res., 10(1):32-39, 2010.

43- Scepanovic M, Calvo-Guirado GL, Markovic A, Delgardo-Ruiz R, Todorovic A, Milicic B, Misic T: A 1 year prospective cohort study on mandibular overdentures retained by mini-dental implants. Eur. J. Oral Implantol., 5(4):367-379, 2012.

44- Jani RM and Bhargava K: A histological comparison of palatal mucosa before and after wearing complete dentures. J. Prosth. Dent., 36: 254-260, 1976.

45- Aziz EA, Amin NR: Cytological study of mucosal tissue reaction to different modern interim esthetic restorations. EDJ, 61:3867-3880, 2015.

46- Beyari MM: Osseointegration of Two Immediately Loaded One Piece Mini Implants to Support Mandibular Overdenture. Inter. J. Surg. Res., 4(2): 19-22, 2014.

47- De Rossi M, Santos CM, Migliorança R, Regalo SCH: All on Four Fixed Implant Support Rehabilitation: A Masticatory Function Study. Clin. Implant Dent. Related Res.,16(4): 594-600, 2014.

48- Heckmann SM, Heussinger S, Linke JJ, Graef F, Pröschel P: Improvement and long-term stability of neuromuscular adaptation in implant-supported overdentures. Clin. Oral Implants Res. , 20(11):1200-1205, 2009. 